\title{
Auxílio-reclusão: o instituto mal(mau)dito das políticas sociais com as políticas penais
}

Luiz Antônio Bogo Chies

\& Rodrigo Azevedo Passos*

Resumo: Tendo por eixo o instituto previdenciário auxílio-reclusão - pago aos dependentes do segurado de baixa renda preso - e a análise das representações sociais construídas a partir dessa prática, a pesquisa enfrenta uma dimensão da complexa interface entre a questão social e as políticas penais. A investigação utilizou como campo empírico o ambiente virtual, coletando dados através das mensagens postadas em blogs ou similares. Como referenciais teóricos privilegiou as perspectivas contemporâneas da sociologia do castigo e da economia política da punição, contemplando aspectos instrumentais e simbólicos das interseções em estudo. Seus resultados constatam a peculiar repulsa social no entorno do auxílio-reclusão, o que favorece apropriações no campo jurídico e político que, emolduradas por tecnicismos e populismos punitivos, ampliam a vulnerabilidade das conquistas sociais.

Palavras-chave: auxílio-reclusão, questão penitenciária, direitos sociais, representações sociais, sociologia do castigo.

\section{Introdução}

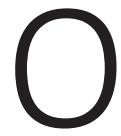
auxílio-reclusão, instituto1 do sistema previdenciário brasileiro - que se torna um paradigmático ponto de interseção das políticas penais com as políticas sociais -, foi içado de sua quase invisível e apática presença no sistema de seguridade social pátrio, em fins de 2009, quando um e-mail - usufruindo de toda a amplitude e o potencial da internet como ambiente de comunicação - o popularizou sob a pecha de "bolsa-bandido". Voltaram-se os olhos (e os interesses) para este seguro social que, em síntese e em sua atual configuração, é pago aos dependentes do segurado de baixa renda na hipótese de sua prisão.

As repercussões da polêmica provocada pelo teor do debate fomentado pelo mencionado e-mail estão na origem desta pesquisa que busca analisar algumas dimensões da interface entre as políticas sociais e penais na expectativa de identificar contradições, complementaridades e contrapontos entre o nível das representações sociais acerca do auxílio-reclusão e o nível concreto de sua efetivação e de suas apropriações.

Na abordagem metodológica, foi realizada uma aproximação entre as áreas da comunicação e das ciências sociais, priorizando como campo empírico a coleta de

\footnotetext{
* Luiz Antônio Bogo Chies é doutor em sociologia pela Universidade Federal do Rio Grande do Sul (UFRGS), professor da Universidade Católica de Pelotas (UCPel) junto ao Programa de Pós-Graduação em Política Social e à graduação em direito.<labchies@ uol.com.br.> Rodrigo Azevedo Passos é graduando em direito pela Universidade Católica de Pelotas (UCPel), bolsista de Iniciação Científica. $<r 7$. rodrigo@hotmail. com>.

1. Adotaremos a terminologia "instituto previdenciário" e não "benefício previdenciário" (como é mais corrente), com o intuito de refutar a conotação de que se trata de algo concedido como favor, graça, privilégio etc., firmando nossa posição de que se trata de um direito instituído em lei e dinamizado pela política.
} 
dados através das mensagens postadas em blogs ou similares. Tratou-se de aproveitar os potenciais destes como artefatos culturais, espaços de sociabilidade, de conversação, de manifestação de opiniões a uma plateia e que, sobretudo, permitem a interlocução através da postagem de comentários (Amaral, Recuero \& Montardo, 2009).

Como referenciais teóricos, situamos a pesquisa vinculada à perspectiva da economia política da penalidade:

\begin{abstract}
Trata-se de uma orientação da criminologia crítica, de derivação principalmente marxista e foucaultiana, que investigou, sobretudo a partir dos anos 1970, a relação entre economia e controle social, reconstruindo as coordenadas da relação que parece manter juntas determinadas formas de produzir e determinadas modalidades de punir (Giorgi, 2006: 31).
\end{abstract}

Contudo, assumimos essa perspectiva a partir de uma concepção renovada (Chies, 2013), a qual nos permite tanto aproveitar a contribuição de seus primeiros representantes - a exemplo de Georg Rusche e Otto Kirchheimer (1999) e Michel Foucault (1991) -, como de autores contemporâneos, dentre os quais o próprio Alessandro de Giorgi (2006) e Loïc Wacquant (2007).

Outros referenciais foram buscados na sociologia do castigo - a exemplo de David Garland (1999) -, bem como na análise do populismo punitivo, a partir de Elena Larrauri (2007) e de David Garland (2008). Também incorporamos abordagens próprias do campo dos sistemas de proteção social (Castel, 1998; Teixeira, 1985; Boschetti, 2003; Pereira, 2009) e alguns estudos pontuais acerca do auxílio-reclusão (Dantas \& Rodrigues, 2009; Raupp, 2009).

Por fim, cumpre registrar que a opção de se trabalhar com a perspectiva das representações sociais, sobretudo na percepção de um ponto de interseção entre políticas sociais e políticas penais, acompanha as orientações de Maria Stela Grossi Porto, quando pontua:

[as representações sociais, possuem um] caráter (ou função) pragmático(a) de orientadora[s] das condutas individuais, de grupos e de instituições públicas (a elaboração de políticas pode ser efeito de determinadas representações) ou privadas. Ou seja, da mesma forma como justificam e orientam práticas dos atores sociais, assim também, a depender de como são apropriadas pelas instâncias institucionais, as representações sociais podem justificar e orientar políticas públicas (Porto, 2010: 64). 
Resgata-se, também, a potencialidade de evidenciar conexões de permanências de sentidos (ainda que em redimensionamentos) como já acenava Serge Moscovici, sendo relevante para este estudo o

poder e a claridade peculiares das [...] representações sociais [que] deriva do sucesso com que elas controlam a realidade de hoje através da de ontem e da continuidade que isso pressupõe (moscovici, 2011: 38).

\section{O auxílio-reclusão e sua conturbada trajetória}

Instituto geneticamente brasileiro - "não se tem notícia da existência em outro país de benefício equivalente" (Dantas \& Rodrigues, 2009: 1) - o auxílio-reclusão pode ser considerado símbolo das próprias trajetórias ambíguas e ambivalentes da proteção social, especialmente se a admitimos como

[...] condição de possibilidade para construir [...] uma sociedade de semelhantes: um tipo de formação social na qual ninguém está excluído, porque cada um dispõe dos recursos e direitos necessários para manter relações de interdependência (e não só de dependência) com todos (Castel, 2011: 117, tradução nossa).

Trata-se de uma trajetória ambivalente, na medida em que se constituiu através de transições e complementaridades entre dois paradigmas originais - o da assistência social e o do seguro social -, os quais, contemporaneamente, são usualmente utilizados em dialogismos redimensionados, que se permitem tanto avanços emancipatórios como permanências perversas.

Se em sua feição original o paradigma clássico da assistência social inclui "o reconhecimento de uma necessidade, e de alguma proposta de aliviá-la", mas atribui "esta situação [a] um problema de caráter do necessitado, razão pela qual a assistência é provida em condições que tentam parcialmente compensar falhas passadas e prevenir contra falhas futuras", sua natureza é "compensatória e punitiva" e se evidencia "na perda de outros direitos inerentes à condição de cidadania [...] ou em restrições de ordem simbólica tais como rituais de degradação, atestados de miséria etc." (Teixeira, 1985: 401). Já o paradigma do seguro social, que lhe é posterior, "tem como característica destinar-se à cobertura da população assalariada com a qual se estabelece uma relação jurídica do tipo contratual" (Teixeira, 1985: 402). Esta transição, e posterior dialogismo de paradigmas, explica-se não por um critério de maior qualidade do segundo em relação ao primeiro, mas sim porque decorre de uma condição histórica diferenciada e específica, a qual se viabiliza e se estrutura com o desenvolvimento da sociedade industrial e a ampliação da abrangência das relações salariais (Castel, 1998). 
E mesmo com os subsequentes avanços da solidariedade social, que produziram tanto os hoje deteriorados sistemas de bem-estar, como o nosso vigente sistema de seguridade social, é importante se ressaltar o que constata Robert Castel, indicando-nos a existência de uma (perversa) permanência histórica em relação ao tratamento das populações sob as diferentes formas da proteção social; uma permanência distintiva, segregacionista e excludente:

As populações que dependem de intervenções sociais diferem fundamentalmente pelo fato de serem ou não capazes de trabalhar, e são tratadas de maneira completamente distinta em função de tal critério (Castel, 1998: 41).

A origem do auxílio-reclusão remete-nos a um período no qual a Previdência Social brasileira estava sendo reestruturada; passava a institucionalizar-se através dos Institutos de Aposentadorias e Pensões (IAPs) cuja filiação, não mais por empresas, passava a ser por categoria profissional. Assim, em 1933, o auxílio-reclusão é criado através do Instituto de Aposentadoria e Pensões dos Marítimos (IAPM), o que permite inferir que nasce da consciência de uma categoria de trabalhadores acerca de sua vulnerabilidade ao risco do encarceramento, instituindo-se como peculiar instrumento de solidariedade.

Em 1960 - quando em curso uma nova reestruturação do sistema brasileiro - o instituto se generaliza através da Lei Orgânica da Previdência Social (Lops), Lei n.․․ 3.807, mantendo sua natureza de seguro social, portanto vinculado à condição de contribuição prévia.

O marco jurídico-político seguinte ocorre em 1988, quando o auxílio-reclusão adquire status constitucional. Através da redação - já modificada - do inciso I do artigo 201, a prisão do segurado insere-se entre os demais riscos sociais que deveriam receber cobertura dos planos de previdência.

Cerca de uma década após alcançar este ápice, instrumentalizando com intensidade inédita no campo da proteção social o princípio da solidariedade inscrito na Constituição Federal (artigo 3이 I), o instituto recebe seu primeiro, e até agora mais contundente, ataque. A Emenda Constitucional n. 20, de 15 de dezembro de 1998, altera a redação do artigo 201 da Magna Carta e o auxílio-reclusão deixa de figurar no mencionado inciso I - onde permaneceram os direitos e as garantias de cobertura, então em claro nível de seguro social - para ser previsto no inciso IV, junto ao salário-família, mas agora restrito aos dependentes dos segurados de baixa renda.

Com cabimento questionável sob o ponto de vista lógico(principiológico)-jurídico, essa alteração legal sustentou-se na perspectiva de que também os institutos previ- 
denciários estariam sujeitos ao princípio da seletividade (artigo 194, III - CF). A noção de seletividade, associada à da distributividade, visa contribuir no equacionamento da desequilibrada relação entre as necessidades sociais e a capacidade econômica do Estado em atendê-las. Permite, portanto, que se estabeleçam critérios de acesso às prestações de "benefícios" e de serviços, numa expectativa de serem concedidos a quem deles efetivamente necessite, otimizando os recursos existentes.

Instituída a reforma constitucional com a clara intenção de contribuir com a contenção do déficit da Previdência, a restrição do alcance do auxílio-reclusão representou também uma intervenção simbólica com reduzido custo de capital político: quem se importa quando são os presos e seus familiares (pessoas rotuladas de infames) os afetados? Não obstante, seu impacto financeiro foi irrisório, conforme instigante estudo elaborado por Emanuel de Araújo Dantas e Eva Batista de Oliveira Rodrigues (2009), no qual analisaram dados que compreendem o período de 1997-2009.

Ocorre que já a natureza de seguro social previdenciário do auxílio-reclusão, vinculado à prévia qualidade de segurado e, portanto, à contribuição, era - e ainda é - em si um elemento limitador de acesso. A seletividade criminal brasileira encarcera, de forma preponderante, membros das camadas socialmente mais vulneráveis e, portanto, menos vinculadas a condições formais e regularizadas de trabalho e acesso à renda.

Não obstante, segmentos do campo jurídico - em especial magistrados - mostraram-se sensíveis aos impactos de desproteção social decorrentes da reforma constitucional. A restrição do acesso foi enfrentada através de corrente jurisprudencial que entendeu ser o limite estabelecido pelo critério "baixa renda" referente à renda bruta mensal do(s) dependente(s) do segurado, e não deste.

Tal linha de entendimento, ainda que bem sucedida no âmbito das decisões da Justiça Federal, e mesmo tendo obtido menção favorável em decisão da 5. a Turma do Superior Tribunal de Justiça (Raupp, 2009: 67-68), não se sustentou perante o Supremo Tribunal Federal (STF) que, em março de 2009, discutindo a matéria por meio de dois recursos extraordinários (REs 587365 e 486413), consolidou por sete votos contra três (com efeito de repercussão geral) a interpretação de que é a renda do segurado (do preso) que deve ser considerada para a concessão do auxílio-reclusão.

Cabe reconhecer que a decisão do STF é coerente com uma perspectiva técnica e lógico-sistêmica do direito previdenciário. Entretanto, é possível inferir que outros fatores também a influenciaram. O ministro-relator Ricardo Lewandowski registra em seu voto: 
2. Acessado através da ferramenta de pesquisa jurisprudencial do site do Supremo Tribunal Federal.

3 A PEC 30/2011 (inteiro teror e justificativa) pode ser acessada através do site: <http://www.camara. gov.br/proposicoesWeb/prop_mostrarintegra;jsessioni$\mathrm{d}=$ A7FE8961C9C6F D3A02F3D639 57629816.node1?codteor $=873634 \&$ filename $=$ PEC +30 /2011>.
Ou seja, o constituinte derivado, à evidência, buscou circunscrever o universo dos beneficiários do auxílio-reclusão apenas aos dependentes dos presos segurados de baixa renda, não a estendendo a qualquer detento, independentemente da renda auferida por este, quiçá como medida de contenção de gastos².

Já no campo propriamente político, o encaminhamento de uma Proposta de Emenda Constitucional (PEC) - numerada como PEC 30/2011³ (de 18 de maio de 2011) constitui-se em significativo exemplo do que podemos considerar como populismo punitivo, na medida em que esta preconiza que o

\begin{abstract}
uso do direito penal pelos governantes [políticos] aparece guiado por três premissas: que maiores penas podem reduzir os delitos [criminalidade]; que as penas ajudam a reforçar o consenso moral existente na sociedade; e que existem ganhos eleitorais produzidos por este uso (Bottoms apud Larrauri, 2007: 10, tradução nossa),
\end{abstract}

com perverso impacto das representações sociais na apropriação política.

A PEC 30/2011, em síntese, busca eliminar o pagamento deste seguro social nos casos em que a condenação criminal do segurado se referir a "prática de tortura, racismo, terrorismo, tráfico ilícito de entorpecentes e drogas afins, pedofilia e crimes definidos como hediondos."

Sem que aqui se entre em maiores detalhes no que diz respeito às diversas inadequações da PEC, o relevante é salientar que se verifica em seu conteúdo e justificativa um diálogo complementar tanto de reforço à oposição do mundo do trabalho com o mundo do crime - oposição que então separa o "cidadão de bem" e aquele que "deu um mau passo" dos "homens infames" e, por fim, dos inimigos (gradualmente desprovidos de direitos perante o grupo) - com a histórica rejeição da proteção social àqueles que, capazes de trabalhar, não o fazem (e, na atualidade, ao menos nos padrões do trabalho útil aos desígnios de uma economia capitalista), como renova os usos políticos que contribuem para o reforço de um imaginário social de segregação e negação de direitos ao preso e a seus próximos (familiares e dependentes), já que busca sustentar sua pretensa legitimidade numa dialogia de complementaridade entre suas propostas e as representações sociais que se constroem.

Está no texto da justificativa da PEC tal busca de pretensa legitimação:

A sociedade tem avaliado e discutido sobre o auxílio-reclusão e entendido que o benefício deve ser pago, mas não de forma aleatória. Há um entendimento geral de que o benefício não deve ser pago a segurados que tenham cometido crimes graves contra a sociedade. 
[...]. Em contrapartida, considerando ser o trabalho um direito do preso, estamos prevendo que o Estado deverá criar oportunidades de emprego para que todos os presos possam trabalhar, inclusive aqueles que não contarão mais com o auxílio-reclusão e que desejem contribuir para o sustento de suas famílias.

Não obstante isso, é importante que se registre também a existência de outra Proposta de Emenda Constitucional - numerada como PEC 420/20094 (de 20 de outubro de 2009) - a qual pretende que se retorne à redação constitucional anterior à EC 20/98, excluindo-se o critério da baixa renda para a concessão do instituto. Segundo sua justificativa:

[...] a adoção de seletividade na concessão do auxílio-reclusão vem denotando, entre outras, as seguintes impropriedades:

u descaracterização de sua natureza de benefício previdenciário sujeito às regras do seguro contributivo obrigatório, ao submeter sua concessão a critérios da assistência social cujos benefícios independem de contribuição e são concedidos a pessoas de baixa renda ou nenhuma renda;

u discriminação e preconceito para com as pessoas de baixa renda, por induzir que apenas estas cometem crimes, são apenadas e recolhidas à prisão;

a punição aos segurados de renda superior ao patamar fixado que foram apenados e recolhidos à prisão, e, por consequência, a seus dependentes.

Com efeito, o que se verifica em toda essa trajetória do auxílio-reclusão é que ele se vem convertendo em paradigmático ponto de interseção das políticas penais com as políticas sociais. Interseção complexa e ambivalente, sujeita a movimentos solidários ou de segregação social.

\section{A pesquisa quanto à formação da base de dados}

Para a coleta dos dados, utilizou-se a ferramenta de pesquisa Google, procedendo-se a busca nos termos-chave "auxílio-reclusão" e "bolsa-bandido" (realizada em 22 de fevereiro de 2011). Foram selecionados e analisados os 50 primeiros endereços de cada termo-chave. Destes 100 sites, após as devidas verificações e exclusões daqueles que apareceram em duplicidade, bem como dos que não tinham seu conteúdo relacionado ao auxílio-reclusão, a amostra se reduziu a 72; destes, 39 apresen-
4 A PEC 420/2009 (inteiro teor e justificativa) pode ser acessada através do site: <http:// www.camara.gov br/proposicoesWeb/ prop_mostrarintegra;jsessionid=E7A5C36650D0550FED$5346932 \mathrm{D} 58 \mathrm{C} 233$. node2?-

codteor $=704342 \&-$ filena-

$m e=P E C+420 / 2009>$ 
tavam postagens de comentários, ou seja, apresentavam a interação e interlocução buscada. Um dos endereços eletrônicos não permitiu o acesso aos comentários, consolidando-se uma base de dados de 38 sites.

Numa primeira categorização, buscou-se diferenciar sites/endereços eletrônicos de órgãos públicos, como o Instituto Nacional de Seguridade Social (INSS), Ministério da Previdência Social, de outros sites informativos (escritórios de advocacia, órgãos e instituições não estatais, por exemplo); distinguiu-se ainda os sites de caráter jornalístico dos demais que se configurassem na modalidade blog. Foram acessados também outros tipos variados de sites, incluindo repositórios de artigos e textos sobre o instituto e, até, de venda de livros; estes foram tipificados na categoria "outros". O Quadro 1 apresenta os dados referentes a essa categorização.

QUADRO 1

DISTRIBUIÇÃO DOS SITES POR TIPOS BÁSICOS

\begin{tabular}{|c|c|c|c|c|}
\hline \multirow[b]{2}{*}{ Tipo de Site } & \multicolumn{2}{|c|}{ Total dos 72 sites } & \multicolumn{2}{|c|}{$\begin{array}{l}\text { Em relação aos } 38 \text { sites } \\
\text { com comentários }\end{array}$} \\
\hline & Número de sites & $\%$ & Número de sites & $\%$ \\
\hline $\begin{array}{l}\text { Informativos de órgãos } \\
\text { estatais }\end{array}$ & 6 & $8,3 \%$ & 0 & - \\
\hline $\begin{array}{l}\text { Informativos de órgãos e } \\
\text { instituições não estatais }\end{array}$ & 5 & $6,9 \%$ & 0 & - \\
\hline Jornalísticos & 6 & $8,3 \%$ & 4 & $10,5 \%$ \\
\hline Blogs ou similares & 36 & $50,0 \%$ & 25 & $65,8 \%$ \\
\hline Fóruns & 6 & $8,3 \%$ & 6 & $15,8 \%$ \\
\hline Outros & 13 & $18,1 \%$ & 3 & $9,0 \%$ \\
\hline Total & 72 & $100,0 \%$ & 38 & $100,0 \%$ \\
\hline
\end{tabular}

Dos dados coletados, destacam-se os sites categorizados como "blogs ou similares", o que confirma a amplitude da repercussão do tema na sociedade, em especial a partir do já mencionado e-mail. Importante mencionar que os sites categorizados como "informativos de órgãos estatais", em especial a partir do termo-chave "auxílio-reclusão", foram os que ocuparam as primeiras posições na lista que resultou da busca feita através do Google.

O segundo foco de análise teve por foco a categorização do tipo da mensagem básica. Ou seja, aquela que, como conteúdo original do site, explicita o sentido comunicacional primeiro e, nos de modalidade interativa (blogs, fóruns etc.), é desencadeadora da interlocução pública.

A característica informativa serviu de base para a categorização do sentido das mensagens. As diferenciações giraram no entorno da perspectiva técnico-informativa 
prevalente nos sites de órgãos e instituições estatais ou não, e do agregar de opiniões ao repasse das informações, quando, então, pode-se perceber os sentidos contrários, favoráveis ou mesmo ambíguos (não expressos com clareza) dos emissores da mensagem em relação à existência ou à operacionalidade do instituto. Em face da contundência de algumas mensagens de opinião contrárias ao auxílio-reclusão, as quais se somavam a informações deturpadas acerca do instituto, gerou-se a categoria "opinativa com informações deturpadas e opinião contrária". Na categoria "outros" foram alocadas mensagens cujos conteúdos eram peculiares e episódicos, tais como a venda de livros; a categoria "legislação" é autoexplicativa. O Quadro 2 apresenta este conjunto de dados no total dos 72 sites e em dois recortes:

\section{QUADRO 2}

DISTRIBUIÇÃO DAS MENSAGENS BÁSICAS POR TIPOS DE SENTIDO

\begin{tabular}{|c|c|c|c|c|c|c|}
\hline \multirow[b]{2}{*}{$\begin{array}{l}\text { Tipo de sentido da mensagem } \\
\text { básica }\end{array}$} & \multicolumn{2}{|c|}{ Total dos 72 sites } & \multicolumn{2}{|c|}{$\begin{array}{l}\text { Em relação aos } 38 \text { si- } \\
\text { tes com comentários }\end{array}$} & \multicolumn{2}{|c|}{$\begin{array}{l}\text { Em relação aos } 36 \\
\text { blogs ou similares }\end{array}$} \\
\hline & $\begin{array}{l}\text { Número } \\
\text { de sites }\end{array}$ & $\%$ & $\begin{array}{l}\text { Número } \\
\text { de sites }\end{array}$ & $\%$ & $\begin{array}{l}\text { Número } \\
\text { de sites }\end{array}$ & $\%$ \\
\hline Informativo técnico & 21 & $29,6 \%$ & 5 & $13,2 \%$ & 3 & $8,3 \%$ \\
\hline $\begin{array}{l}\text { Informativo com opinião } \\
\text { contrária }\end{array}$ & 7 & $9,9 \%$ & 5 & $13,2 \%$ & 7 & $19,4 \%$ \\
\hline $\begin{array}{l}\text { Informativo com opinião } \\
\text { favorável }\end{array}$ & 3 & $4,2 \%$ & 1 & $2,6 \%$ & 3 & $8,3 \%$ \\
\hline Informativo com opinião ambígua & 7 & $9,9 \%$ & 4 & $10,5 \%$ & 6 & $16,7 \%$ \\
\hline Informativa de estilo jornalístico & 5 & $7 \%$ & 4 & $10,5 \%$ & 1 & $2,8 \%$ \\
\hline $\begin{array}{l}\text { Opinativa com informações } \\
\text { deturpadas e opinião contrária }\end{array}$ & 16 & $22,5 \%$ & 15 & $39,5 \%$ & 14 & $38,9 \%$ \\
\hline Legislação & 2 & $2,8 \%$ & 0 & - & 0 & - \\
\hline Outros & 10 & $14,1 \%$ & 4 & $10,5 \%$ & 2 & $5,6 \%$ \\
\hline Total & 72 & $100,0 \%$ & 38 & $100,0 \%$ & 36 & $100,0 \%$ \\
\hline
\end{tabular}

Fonte: Pesquisa direta, 2011.

É de se destacar os números referentes à categoria "opinativa com informações deturpadas e opinião contrária", na qual os blogs e similares são a quase totalidade das ocorrências: 14 das 16.

Nos 38 sites com comentários, acentuou-se a prevalência das mensagens básicas que já desencadeiam a interlocução num sentido desfavorável ao auxílio-reclusão. 15 sites $(39,5 \%)$ têm sua mensagem básica vinculada à categoria "opinativa com informações deturpadas e opinião contrária", e 5 deles (13,2\%) têm a mensagem básica "informativa com opinião contrária". O somatório representa 52,7\% dos sites (20 dos 38).

Estes 38 sites geraram 784 comentários/mensagens, dos quais 615 foram analisados. Foram excluídas as repetições de postagens e meros reforços de conteúdos 
por internautas que já haviam se manifestado na interlocução, além de comentários que - apesar de localizados no contexto da discussão sobre o instituto - não abordavam, sequer indiretamente, a questão. Quanto a esses dados amplos, ainda se pode inferir que foram 603 distintos internautas os emissores de tais mensagens.

As mensagens básicas destes 38 sites foram inseridas nos respectivos endereços eletrônicos entre 18 de janeiro de 2006 e 20 de fevereiro de 2011. No entanto, em 30 deles $(78,9 \%)$ as mensagens iniciais tiveram sua inserção datada a partir de dezembro de 2009, situação que as relaciona com o desencadear da discussão motivada pelo e-mail que denominava o instituto do auxílio-reclusão como "bolsa-bandido".

Estes 30 sites continham 750 comentários postados, gerando 595 das 615 mensagens analisadas. Dados que nos reforçam a credibilidade dos procedimentos adotados para a construção do campo empírico da pesquisa.

\section{Em busca das representações sociais: as 615 postagens e suas mensagens}

O Quadro 3 apresenta as 615 mensagens numa primeira categorização de seus conteúdos. Esta as distingue como de conteúdo "negativo" (contrário, desfavorável), "positivo" (favorável) ou "ambíguo" à existência e aos critérios de operacionalidade do instituto; foram, ainda, utilizadas as categorias "sem opinião" (quando, por exemplo, havia perguntas mais casuísticas sobre sua aplicação, ou mesmo à margem do tema) e "comentários de outras postagens", quando apenas isto fizeram, pouco agregando em outros termos analíticos.

QUADRO 3

DISTRIBUIÇÃO DAS MENSAGENS, POR CATEGORIAS AMPLAS DE CONTEÚDO

\begin{tabular}{|l|c|c|}
\hline Tipo de sentido da mensagem básica & Número de comentários & $\%$ \\
\hline Negativo & 238 & 38,7 \\
\hline Positivo & 89 & 14,5 \\
\hline Ambíguo & 45 & 7,3 \\
\hline Sem opinião & 178 & 28,9 \\
\hline Comentaram outras postagens & 65 & 10,6 \\
\hline Total & 615 & $100,0 \%$ \\
\hline Fonte: Pesquisa direta, 2011. & & \\
\hline
\end{tabular}

Ao se desencadear a apresentação e análise a partir das mensagens de conteúdo explicitamente negativo (haja vista sua representatividade: $38,7 \%$ ), buscou-se desdobrá-las em subcategorias de sentido. A primeira utilizada refere-se à "oposição do mundo do trabalho com o mundo do crime". Trata-se de um sentido que, elaborado 
sobretudo a partir das análises de José Ricardo Ramalho (2002), acaba por ser encontrado tanto em mensagens de opinião negativa como positiva. Tem em comum, além desta imediata oposição entre o bem e o mal, o bom e o mau (o trabalho/ trabalhador versus o ócio-crime/delinquente, o cidadão versus o não cidadão), a capacidade de resgatar representações que remontam à primeva distinção entre os que são realmente merecedores de assistência e os "mendigos válidos" - estes como não merecedores de proteção social - já existente desde Poor Laws inglesas 5 . Relacionam-se com as abordagens foucaultianas sobre a delinquência e os homens infames. Traduzem-se em postagens ${ }^{6}$ como:

Eita, Brasil brasileiro!!! Este país aguenta tudo, né? Bolsa para filho de bandido? Era só o que faltava para completar a bagunça!!! Enquanto isso, pessoas pobres, honestas, bom caráter vivem à míngua. Agora, no meu entendimento, só nos resta pedir a proteção de Deus!!! (AR-08).

[...] e aparece um meliante e liquida este cidadão; nunca os direitos humanos defenderam qualquer ajuda para a família dele, trabalhador/honesto. Minha mente reluta e não entende quem defende o meliante e esquece o cidadão honesto [...] (AR-25).

A segunda subcategoria é uma emergência do campo empírico, tendo como sentido explícito a perspectiva de que os custos e ônus da prisão, o que também envolve o sustento de seus familiares, devem ser suportados pelo próprio preso ou por sua família. Também emergente foi a subcategoria que se traduziu como "dinheiro público para que não entre no crime".

As duas subcategorias seguintes - "estimula a criminalidade" e "less egilibility" - referem-se ao argumento de que o instituto é um estímulo à criminalidade bem como a uma adesão às expectativas do princípio less egilibility (Rusche \& Kirchheimer, 1999), entendido como o que estabelece que as condições das prisões devem ser sempre piores do que as condições de vida das camadas menos favorecidas da população, a fim de que a vida no cárcere seja menos desejável (de menor elegibilidade) à vida que se subjuga às estruturas, relações e dinâmicas da sociedade capitalista:

Lamento, mas discordo de qualquer comentário que defenda e justifique este auxilio, da forma que o Governo e INSS o implantou!!! é realmente um seguro bandido, é proteção a bandido, traficante, assaltante e tudo de bom que eles acham que podem nos prejudicar... é incitação ao crime... É demonstrar que não vale apena ser cidadão honesto [...] (AR-12).

Nesse sentido, cabe registrar que muitas postagens avançam em sua oposição, demonstrando também outros elementos de um senso comum que desconhece a
5. As Poor Laws ou Leis dos Pobres - constituem um sistema legal de assistência aos pobres que se desenvolveu na Inglaterra já a partir de períodos medievais (a Ordenança dos Trabalhadores, decreto emitido por Eduardo III em 1349, é mencionado como marco inicial), passando por importantes legislações no período da dinastia Tudor (1485-1603).

O sistema, com

suas sucessivas reformas, existiu até o surgimento do Estado de bemestar social, após a Segunda Guerra Mundial.

6. Nas citações, interferiu-se o menos possível no estilo de escrita, já que são também reveladores de sentidos. Para identificar a origem das mensagens, utilizou-se o seguinte sistema: para os sites acessados através do termo-chave "auxílio-reclusão", a sigla AR seguida do número de ordem de sua aparição no dia da busca, ou seja: o primeiro endereço eletrônico foi identificado como AR-01, o segundo, AR-02 etc. Para os acessados através do termo-chave "bolsa-bandido" o procedimento é similar, adotando-se a sigla BB. 
realidade da questão penitenciária no Brasil, produzindo sobre as prisões um imaginário irreal:

[...]. Mais vale se ficar desempregado, partir pra bandidagem, lá vc terá melhor comida do que tinha em sua casa, afinal o que ganhava era pra sustentar muitas bocas... Vai ter assistência médica, jurídica, comidinha quente todos os dias, sem precisar fazer absolutamente nada. Ah, e se houver rebeliões, queime o colchão, vc receberá outro novinho sem ter que pagar por ele. Quem paga somos nós (AR-07).

O argumento de que é a família da vítima, ou mesmo a própria vítima, que deve receber algum tipo de auxílio, e não a família daquele que comete o delito, também foi observado com significância, motivando o registro:

[...] não há que se falar em ajudar a família de um assassino, e sim a família da vítima.

Os poucos brasileiros que ainda prestam precisam lutar juntos para acabar com essa vergonha de auxílio-reclusão patrocinada pelo INSS com o nosso dinheiro. Malditos governantes (AR-12).

Expressiva se demonstrou a subcategoria denominada de "tolerância zero", na qual as postagens assumem, em regra, além de um rigor punitivo intransigente, um tom de extrema passionalidade:

É imoral! Somos todos mesmo trouxas!

Depois quando alguém diz que "bandido bom é bandido morto" vem alguém (da área do direito) dizer que é "apologia de crime". Porém digo mais: bandido bom é bandido morto e dissolvido no ácido pra não termos que pagar pelo funeral dele. Mas o ácido eu pagaria satisfeita! (AR-35).

Por fim, na subcategoria "outros" foram incluídas as postagens com conteúdos não abarcáveis pelas categorias anteriores. Nesta, foram frequentes as manifestações fundamentadas na crença de que a criação do instituto se devia a um ou outro governo e, portanto, consubstanciavam críticas mais de ordem político-partidárias.

No Quadro 4 lançamos a distribuição das mensagens nessas subcategorias. Antes de apresentá-lo, algumas considerações:

a. As 238 mensagens foram postadas em 31 dos 38 sites; destes, 16 acessados pelo termo-chave "auxílio-reclusão", 13 pelo termo-chave 
"bolsa-bandido" e dois por ambos. No Quadro 4, ao lado dos números totais, apresentamos um comparativo entre os resultados referentes ao conjunto dos sites acessados a partir de cada termo-chave; os dois sites acessados por ambos termos-chave estão agregados na coluna "auxílio-reclusão".

b. Algumas mensagens trouxeram mais de um dos sentidos categorizados, portanto o somatório dos números apresentados em cada subcategoria extrapola o de 238 mensagens; contudo, é em relação a este total que serão apresentados os percentuais, na medida em que o que nos interessa é a produção de sentidos e representações sociais.

QUADRO 4

DISTRIBUIÇÃO DOS CONTEÚDOS DAS MENSAGENS DE POSICIONAMENTO NEGATIVO (CONTRÁRIO) EM RELAÇÃO AO AUXílIO-RECLUSÃO POR SUBCATEGORIAS DE SENTIDO

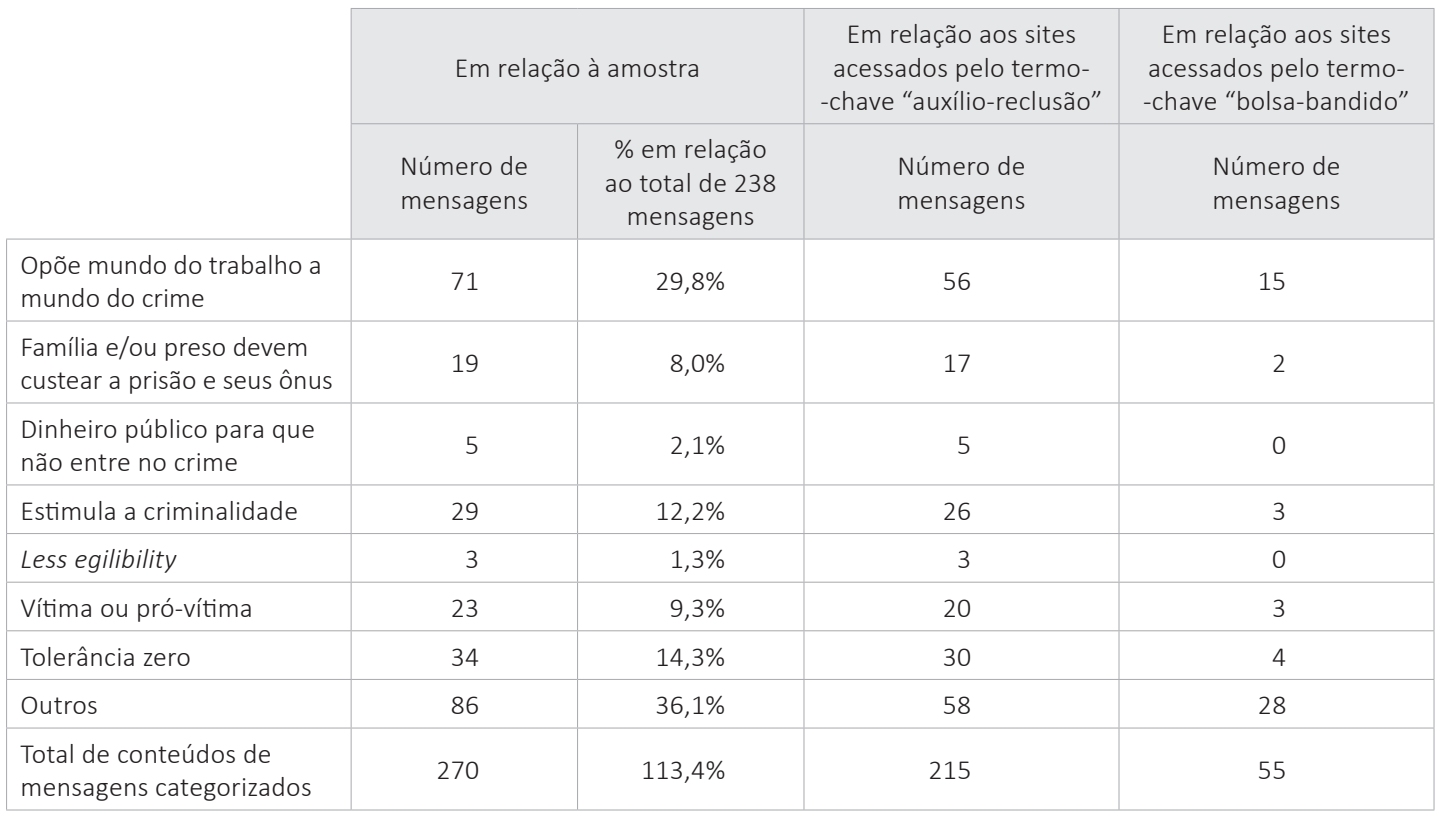

Fonte: Pesquisa direta, 2011.

Em relação às postagens com conteúdo de sentido positivo (89), duas subcategorias se evidenciaram. A primeira enfatiza a "garantia de sobrevivência da família". Envolve, entretanto, uma diversidade de fundamentações, as quais transitam da compaixão e da caridade (em sua maioria) ao reconhecimento da igualdade dos sujeitos num Estado de direito. Nesta última fundamentação, quase isolada, tem-se a seguinte postagem: 
As críticas da hipocrisia me escandalizam mais que a bandidagem. Os familiares do criminoso ficam desamparados e precisam de algo ou alguém que os ampare, pois o responsável pela sua criação e educação está preso, impossibilitado de o fazer. Não é maltratando os familiares do preso que se resolve o problema da criminalidade. O buraco é mais embaixo. Os hipócritas que perguntam: "E a família das vítimas?", lutem pelos seus direitos sem retirar os direitos dos outros. Todos os seres humanos têm direitos e deveres, não podemos acusar os bandidos ou seus familiares se, quem de direito, não beneficia todos com a mesma proporção. Devemos perguntar primeiro: Por que as pessoas cometem atos delituosos? Esta é a questão! (AR-29).

A segunda traduz-se na relação "contribuiu, deve receber". Trata-se de um sentido que focaliza mais a natureza contratual e de seguro social contributivo do instituto e menos dimensões de solidariedade e proteção social. Não obstante seja favorável à operacionalidade do auxílio-reclusão, não está isenta das ambiguidades já verificadas.

Todos esses benefícios só serão concedidos para os segurados (quem contribuiu) ou seus dependentes. Nada mais justo (AR-18).

[...] o benefício é concedido para o sustento dos menores e somente se o infrator contribuiu com o INSS, não é um benefício concedido a um mala sem alça que foi preso, nosso popular "vagabundo" (AR-19).

Quanto às mensagens de sentido ambíguo (45), categoria na qual a diversidade e forma de exposição dos conteúdos nos levou a incluir a maioria das postagens na genérica subcategoria "outros" - foi possível identificar, em especial nos sites acessados pelo termo-chave "auxílio-reclusão", a emergência de três sentidos relevantes. Dois deles mais associados a uma percepção negativa do instituto - a oposição do mundo do trabalho ao mundo do crime; e remetê-lo à família do preso, ou a ele próprio, o dever de custeio da prisão - e um terceiro associado a uma perspectiva positiva, no sentido de que o instituto se vincula a uma dívida social para com o condenado.

O Quadro 5, com características similares às do Quadro 4, busca apresentar uma visão de síntese desses dados.

Por fim, também em síntese, o Quadro 6 apresenta um detalhamento em relação as mensagens categorizadas como "sem opinião" e "comentaram outras postagens".

Todos esses dados permitem-nos vislumbrar um panorama compreensivo da repulsa social que recai sobre o instituto, sendo esta amparada sobretudo no estabelecimento (ou permanência histórica) de uma fronteira que separa o bem do mal a 


\section{QUADRO 5}

DISTRIBUIÇÃO DOS CONTEÚDOS DAS MENSAGENS DE POSICIONAMENTO POSITIVO (FAVORÁVEL) E AMBíGUO EM RELAÇÃO AO AUXílIO-RECLUSÃO, POR SUBCATEGORIAS DE SENTIDO

\begin{tabular}{|c|c|c|c|c|c|c|c|c|}
\hline & \multicolumn{4}{|c|}{ Posicionamento positivo (favorável) } & \multicolumn{4}{|c|}{ Posicionamento ambíguo } \\
\hline & \multicolumn{2}{|c|}{ Em relação aos 38 sites } & \multirow{2}{*}{$\begin{array}{c}A^{*} \\
\text { Número } \\
\text { de men- } \\
\text { sagens }\end{array}$} & \multirow{2}{*}{$\begin{array}{c}\text { B** } \\
\text { Número } \\
\text { de men- } \\
\text { sagens }\end{array}$} & \multicolumn{2}{|c|}{ Em relação aos 38 sites } & \multirow{2}{*}{$\begin{array}{c}A^{*} \\
\text { Número } \\
\text { de men- } \\
\text { sagens }\end{array}$} & \multirow{2}{*}{$\begin{array}{c}\mathrm{B}^{* *} \\
\text { Número } \\
\text { de men- } \\
\text { sagens }\end{array}$} \\
\hline & $\begin{array}{l}\text { Número } \\
\text { de men- } \\
\text { sagens }\end{array}$ & $\begin{array}{c}\% \text { em } \\
\text { relação ao } \\
\text { total de } 89 \\
\text { mensagens }\end{array}$ & & & $\begin{array}{l}\text { Número } \\
\text { de men- } \\
\text { sagens }\end{array}$ & $\begin{array}{c}\% \text { em } \\
\text { relação ao } \\
\text { total de } 45 \\
\text { mensagens }\end{array}$ & & \\
\hline $\begin{array}{l}\text { Garantia de sobrevivência } \\
\text { da família }\end{array}$ & 44 & $49,4 \%$ & 35 & 9 & - & - & - & - \\
\hline Contribuiu, deve receber & 25 & $28,1 \%$ & 21 & 4 & - & - & - & - \\
\hline Outros & 20 & $22,5 \%$ & 14 & 6 & 34 & $75,6 \%$ & 27 & 7 \\
\hline $\begin{array}{l}\text { Opõe mundo do trabalho } \\
\text { com mundo do crime }\end{array}$ & - & - & - & - & 6 & $13,3 \%$ & 6 & 0 \\
\hline $\begin{array}{l}\text { Família e ou preso devem } \\
\text { custear a prisão e seus ônus }\end{array}$ & - & - & - & - & 2 & $4,4 \%$ & 2 & 0 \\
\hline Dívida social & - & - & - & - & 3 & $6,7 \%$ & 3 & 0 \\
\hline Total & 89 & $100,0 \%$ & 70 & 19 & 45 & $100,0 \%$ & 38 & 7 \\
\hline
\end{tabular}

* A) Em relação aos 22 sites acessados pelo termo-chave "auxílio-reclusão". Incluídos neste recorte os 2 (dois) sites que foram acessados a partir de ambos os termos-chave.

** B) Em relação aos 16 sites acessados pelo termo-chave "bolsa bandido".

Fonte: Pesquisa direta, 2011.

\section{QUADRO 6}

DISTRIBUIÇÃO DOS CONTEÚdOS DAS MENSAGENS "SEM OPINIÃO" E "CoMEntaram outras Postagens", POR SUbCATEgorias

\begin{tabular}{|c|c|c|c|}
\hline Categoria ampla & Subcategoria & $\begin{array}{l}\text { Número de mensagens } \\
\text { em relação aos } 38 \text { sites }\end{array}$ & $\begin{array}{c}\text { Percentual em relação ao total } \\
\text { de mensagens da categoria }\end{array}$ \\
\hline \multirow[t]{2}{*}{ Sem opinião } & $\begin{array}{l}\text { Perguntas de familiar ou co- } \\
\text { nhecido, para esclarecimento } \\
\text { de dúvidas }\end{array}$ & 90 & $50,6 \%$ \\
\hline & Outros conteúdos & 88 & $49,4 \%$ \\
\hline \multicolumn{2}{|c|}{ Total de conteúdos de mensagens categorizados } & 178 & $100,0 \%$ \\
\hline
\end{tabular}

\begin{tabular}{|c|c|c|c|}
\hline \multirow{5}{*}{$\begin{array}{l}\text { Comentaram outras posta- } \\
\text { gens }\end{array}$} & Critica quem é contra & 17 & $26,2 \%$ \\
\hline & Critica quem é a favor & 7 & $10,8 \%$ \\
\hline & Concorda com quem é contra & 4 & $6,1 \%$ \\
\hline & Concorda com que é a favor & 0 & - \\
\hline & Corrige informações & 37 & $56,9 \%$ \\
\hline \multicolumn{2}{|c|}{ Total de conteúdos de mensagens categorizados } & 65 & $100,0 \%$ \\
\hline
\end{tabular}

Fonte: Pesquisa direta, 2011. 
partir dos estereótipos do bom e do mau, das caricaturas do "cidadão de bem" e do "homem infame", as quais nos conduzirão ao digno de cidadania e ao indigno, o outro, o estranho e, por fim, ao inimigo, até mesmo passível de eliminação.

Mas, para além disso, a dinâmica das interlocuções nos sites ainda nos revela outras dimensões preocupantes da repulsa social que gravita no entorno do auxílio-reclusão e que repercutem em suas apropriações políticas. Dessas, e nos limites do presente artigo, duas merecem destaque.

A primeira remete-nos à percepção de que as representações sociais que se constroem no entorno do auxílio-reclusão manifestam que a reflexividade social sobre o fenômeno da criminalidade está significativamente desprovida de uma criticidade quanto aos favorecimentos estruturais da sociedade contemporânea tanto no que se refere à constituição da delinquência, como em relação à atuação - seletiva e excludente - do sistema de justiça criminal. No eixo das manifestações que conectam o auxílio-reclusão e a família do preso isso se evidencia em diferentes níveis de sutilezas e sofisticações perversas.

No plano das postagens de opinião explicitamente negativa ao instituto, a família do preso é muitas vezes contaminada pela infâmia que sobre ele recai; não são raros os comentários que as culpabilizam pela situação na qual se encontram: sobretudo esposas e companheiras.

Ultraje total. Mesmo que seja um auxílio temporário, prisão não é colônia de férias. O criminoso tem de pagar pelo que fez, e não ser "auxiliado", isto é um incentivo à criminalidade nesse país formado por corruptos e ladrões. Se uma pessoa escolheu casar ou se juntar com um delinquente, os demais cidadãos de bem não têm nada com isso e não devem arcar com essa escolha infeliz (BB-09).

Mesmo nas mensagens que se permitiram categorizar como de sentido positivo o auxílio-reclusão, a postura em relação às famílias é muitas vezes paradoxal, com significativo conteúdo de uma profilaxia utilitária de higienização dos infames:

Concordo é melhor o benefício do que ver crianças trabalhando, e melhor crianças na escola do que crianças roubando para comer, é melhor a mulher passar a noite com os filhos do que passar a noite se prostituindo!!! (AR-12).

[...] essa medida é correta sim, pra evitar que o filho desse bandido também vire bandido. Se a gente for pesquisar a vida desses bandidos, vamos ver que a maioria é gente que não teve pai, ou o pai tava preso durante toda a infância, a mãe, sem instrução, tinha que trabalhar e deixar os filhos em casa, onde eles se envolvem com o crime. A gente tem que parar pra pensar que a nossa sociedade tá 
muito longe de ser perfeita, é muito desigual e injusta. Pra mim, pobre não podia ter filho, mas aí me chamam de radical, então tem que remediar a situação (AR-18).

Por fim, um segundo aspecto a ser observado é o paradoxo que se perfaz através dos opostos: repulsa ao esclarecimento versus necessidade de conhecimento.

Se a recente visibilidade do auxílio-reclusão e a intensificação de seu debate no ambiente virtual foi motivada por um e-mail que continha uma série de informações deturpadas, muitos internautas adotaram essas (des)informações como a verdade. E isto, não obstante muitas das mensagens incluírem em seus conteúdos a correção dos requisitos e critérios de aplicação e efetivação do auxílio-reclusão, até mesmo remetendo os interlocutores ao site da Previdência Social, no qual as informações oficiais estão disponíveis (das 65 mensagens categorizadas como "comentaram outras postagens" - Quadro 6-, 37 tinham como conteúdo exclusivo a correção das informações deturpadas).

A repulsa ao esclarecimento serve-nos de alerta em relação não só à passionalidade do debate, mas, ainda, à internalização de uma abominação social que é permissiva e favorecedora de políticas de exclusão social.

[...] isso e uma vergonha total e não adianta dizer q o post é falso e nao sei oq, fikar querendo defender esses lixos, pra começar nem sei oq bandido vai fazer na cadeia, ja q e sustentado com nosso dinheiro, tinha q ser morto, e antes de ser morto, fazê-lo trabalhar para pagar as balas gastas nele, [...] (AR-35).

No contraponto da repulsa ao esclarecimento está a carência de informação. Das 178 mensagens categorizadas como "sem opinião" (Quadro 6), 90 eram perguntas de familiares ou conhecidos de presos solicitando informações acerca do auxílio-reclusão.

Na interseção da questão social com a questão penitenciária há, pois, uma demanda tácita por proteção social. Uma demanda que se agiganta proporcionalmente ao incremento das práticas de encarceramento que se verificam num Brasil que, já no decorrer de 2011, superou a marca de meio milhão de presos e, só nos últimos dez anos, promoveu a elevação da taxa de aprisionamento de 133 para mais de 270 pessoas por 100 mil habitantes?

Quais são os impactos e as apropriações políticas que estes dados - bem como aquele apresentado no panorama compreensivo das representações sociais acerca 7. Dados acessados junto ao site do Departamento Penitenciário Nacional. do auxílio-reclusão - estão produzindo em nossa realidade? 


\section{Considerações finais:}

8. As workhouses, ou casas de trabalho, desenvolveramse não só na Inglaterra, mas também em outras partes da Europa. $\mathrm{Na}$ Inglaterra, apesar de seus antecedentes já nas primeiras legislações que compõe as chamadas Poor Laws, elas "florescem" sobretudo a partir do Act for the Relief of the Poor, de 1601. São locais de encarceramento dos "pobres, mendigos, vadios", no qual trabalhavam como condição de seu sustento.

9. Nesse sentido, cabe destacar os trabalhos de Vinicius Caldeira Brant (1994), Edmundo Campos Coelho (2005), Augusto Thompson (2007).
Nossa perspectiva parte da premissa de que, historicamente, existe uma conexão não só entre punição e estrutura social, mas também entre proteção social e práticas de segregação penal. São vínculos que, desvelados, não apenas permitiram que se evidenciassem as workhouses ${ }^{8}$ como instituições inseridas na origem das prisões modernas (Rusche \& Kirchheimer, 1999; Foucault, 1991; Melossi \& Pavarini, 1980; Castel, 1998), como também as contemporâneas transições de um Estado providência para um Estado penitência (Wacquant, 2007).

Tal premissa não significa associar, de forma simplista, pobreza e criminalidade, mas sim valorizar tanto as pioneiras percepções de Rusche e Kirchheimer, ao mencionarem que a "história da política pública para mendigos e pobres somente pode ser compreendida se relacionamos a caridade com o direito penal" (Rusche \& Kirchheimer, 1999: 52), como as mais contemporâneas perspectivas, no sentido de que a "política penal e a política social não podem ser consideradas como processos autônomos e independentes, pois respondem ao mesmo conjunto de determinações presentes na sociedade" (Wolff, 2005: 8).

No Brasil expressões dessa conexão - como a relação entre a seletividade das práticas de controle social e as dimensões de vulnerabilidades que se podem verificar nos indivíduos e grupos selecionados - já são há muito reconhecidas no campo do enfrentamento cognitivo e político das práticas de controle social punitivo ${ }^{9}$ e nos permitem considerar que a contemporânea questão penitenciária evidencia-se, de forma significa e com preponderância, nas interseções das esferas da política penal, criminal e social (Chies, 2013).

Nesse reconhecimento de conexões, o que nossa pesquisa demonstra é que a relação entre as políticas sociais e as políticas penais se constitui através de uma tessitura complexa de elementos, discursos, representações sociais, intervenções e práticas, os quais dialogam para, muitas vezes, complementarem-se em domínios de segregação e de exclusão social.

Nesta relação, as sutilezas podem apresentar-se tão ou mais perversas do que os explícitos projetos, especialmente quando se realizam através de máscaras retóricas sedutoras e da apropriação utilitária de representações sociais que deveriam ser mais um alvo prioritário de esclarecimento político-reflexivo do que um sustentáculo acrítico de pseudolegitimação. E o auxílio-reclusão pode ser considerado como exemplo paradigmático dessas perversas sutilezas.

Em sua conturbada e ambivalente trajetória, o auxílio-reclusão nasce da consciência de uma categoria trabalhadora acerca de sua vulnerabilidade ao risco do encarce- 
ramento; amplia-se como instrumento de proteção social (ainda que limitado por sua natureza de seguro social) até atingir o status de direito constitucional, em 1988 (trajetória que confere um significado menos retórico ao princípio da pessoalidade da pena inscrito no inciso XLV do artigo 5ㅇ da Magna Carta: "nenhuma pena passará da pessoa do condenado [...]"). É vulnerável, entretanto, e vem perdendo gradualmente sua potência de direito/instrumento humano-dignificante.

Nos ataques que sofridos, estratégias de sutil perversidade se verificam: máscaras retóricas sedutoras manifestam-se tanto no argumento da contenção do déficit da Previdência Social, na EC 20/1998, como no da perspectiva da oferta do trabalho prisional que se insere na PEC 30/2011; a apropriação utilitária de representações sociais é mais flagrante no caso da PEC 30/2011 - o que nos evidencia um caso exemplar de populismo punitivo ${ }^{10}$ - mas também permitiu a ausência de resistências quando da consolidação da EC 20/1998.

Mas, como nossa pesquisa também demonstra, a vulnerabilidade do instituto não se constitui apenas perante as possibilidades da perversidade estatal e/ou eleitoreira; a sociedade civil não cumpre aqui um simples papel de inerte vítima; com sua repulsa social, contribui significativamente para a degradação do auxílio-reclusão como instrumento de proteção social.

Logo, ainda que pudesse ser poético concluir este artigo com a denúncia de que é em quase silêncio social que a agonia do auxílio-reclusão se produz, haja vista a omissão da sociedade em resistir aos ataques que contra ele são dirigidos, tal imagem é ilusória, tendo em vista o volume das vozes que o rejeitam (ainda, e no mais das vezes, de forma acrítica e irreflexiva).

Esta repulsa social - como um sentido congregante das representações sociais que emergem em nossa pesquisa - não é passível de ser explicada por uma única via. É tecida por diversos fios que se unem em trajetórias históricas, com permanências e mutabilidades. Assinala, entretanto, como um exemplo contundente, mais um desafio não só para o enfrentamento da questão penitenciária, mas para o amplo campo das políticas públicas e sociais: o de compreender, para então melhor operar, as conexões complexas existentes tanto entre as diversas áreas das políticas (em nosso foco entre as políticas sociais e as penais), como também (e sobretudo) entre estas e a própria sociedade que as rejeita ou recepciona, retroalimentando, assim, configurações antagônicas de dominação/segregação/exclusão ou de emancipação e sociabilidades de dignificação do ser humano.
10. Mesmo que a PEC 30/2011 ainda não tenha sido aprovada (e talvez sequer 0 seja), retomamos a perspectiva de sua associação com as correntes do populismo punitivo na medida em que estas representam "uma postura ou tática política, adotada para a obtenção de dividendos políticos de curto prazo"

(Garland, 2008: 372). Assim, prosseguindo na compreensão de Garland: "Novas leis e políticas são rapidamente instituídas [ou, ao menos, propostas] sem consulta prévia aos profissionais do sistema penal e o controle da agenda política por tais profissionais fo consideravelmente reduzido por um estilo populista de fazer política" (Garland, 2008: 372) 
Abstract: Focusing on the analysis of the social security system institute of Imprisonment - paid to the dependent of the insured low-income - and the analysis of the social representations that are built on it, the research faces a dimension of the complex interface between the social and criminal policies. The empirical field used in the research was the virtual environment, collecting data through messages posted on blogs or the like. As theoretical references, it privileged the contemporary perspectives of sociology of punishment and the political economy of punishment, covering instrumental and symbolic aspects of the studied intersections. Its results perceive the peculiar social revulsion concerning imprisonment-relief, which favors appropriations in the legal and political fields which, framed by technicalities and punitive populism, expand the vulnerability of the social achievements.

Keywords: Imprisonment-relief, prison question, social rights, social representations, sociology of punishment.

\section{Referências}

AMARAL, Adriana; RECUERO, Raquel; MONTARDO, Sandra Portella. Blogs: mapeando um objeto. In: AMARAL, Adriana; RECUERO, Raquel; MONTARDO, Sandra Portella (Orgs.). Blogs.com: estudos sobre blogs e comunicação, p. 27-53. São Paulo: Momento Editorial, 2009.

BOSCHETTI, Ivanete Salete. Implicações da reforma da Previdência na Seguridade Social Brasileira. Revista Psicologia e Sociedade, v. 15, n. 1, p. 57-96. Porto Alegre, 2003.

BRANT, Vinicius Caldeira. O trabalho encarcerado. Rio de Janeiro: Forense, 1994.

CASTEL. Robert. La inseguridad social: que es estar protegido? Buenos Aires: Manantial, 2011.

Vozes, 1998.

CHIES, Luiz Antônio Bogo. A questão penitenciária. Tempo Social, v. 25, n. 1, p.15-36, Jun. 2013.

COELHO, Edmundo Campos. A criminalização da marginalidade e a marginalização da criminalidade. In: COELHO, Edmundo Campos. A oficina do diabo e outros estudos sobre criminalidade, p.255-288. Rio de Janeiro: Record, 2005.

DANTAS, Emanuel de Araújo; RODRIGUES, Eva Batista de Oliveira. Auxílio-reclusão: uma abordagem conceitual. Informe de Previdência Social, v. 21, n. 6, p.1-13, Jun. 2009.

FOUCAULT, Michel. Vigiar e punir: nascimento da prisão. Petrópolis: Vozes, 1991.

GARLAND, David. A cultura do controle: crime e ordem na social na sociedade contemporânea. Rio de Janeiro: Revan, 2008. 
GARLAND, David. Castigo y sociedad moderna - un estudio de teoría social. México: Siglo XXI, 1999.

GIORGI, Alessandro de. A miséria governada através do sistema penal. Rio de Janeiro: ICC; Revan, 2006.

LARRAURI, Elena. Populismo punitivo... y como resistirlo. Revista de Estudos Criminais, n. 25, p. 9-25. Porto Alegre, 2007.

MELOSSI, Dario; PAVARINI, Massimo. Carcel y fábrica: los orígenes del sistema penitenciario, siglos XVI-XIX. México: Siglo Veintiuno Editores, 1980.

MOSCOVICl, Serge. Representações sociais: investigações em psicologia social. 8. ed. Petrópolis: Vozes, 2011.

PEREIRA, Potyara. Política social: temas \& questões. São Paulo: Cortez, 2009.

PORTO, Maria Stela Grossi. Sociologia da violência. Brasília: Verbana, 2010.

RAMALHO, José Ricardo. O mundo do crime: a ordem pelo avesso. São Paulo: IBCCrim, 2002.

RAUPP, Daniel. Auxílio-reclusão: inconstitucionalidade do requisito baixa renda. Revista CEJ, Ano XIII, n. 46, p. 62-70, Jul.-Set. 2009.

RUSCHE, Georg; KIRCHHEIMER, Otto. Punição e estrutura social. Rio de Janeiro: Freitas Bastos, 1999.

TEIXEIRA, Sonia Maria Fleury. Política social e democracia: reflexões sobre o legado da seguridade social. Caderno de Saúde Pública, v. 1, n. 4, p. 400-417, Out.-Dez. 1985.

THOMPSON, Augusto. Quem são os criminosos. 2. ed. Rio de Janeiro: Lumen Juris, 2007.

WACQUANT, Loïc. Punir os pobres: a nova gestão da miséria nos Estados Unidos [A onda punitiva]. Rio de Janeiro: Revan, 2007.

WOLFF, Maria Palma. Antologias de vidas e histórias na prisão: emergência e injunção de controle social. Rio de Janeiro: Lumen Juris, 2005. 
